\title{
P16 Immunohistochemical Expression Analysis
}

National Cancer Institute

\section{Source}

National Cancer Institute. p16 Immunohistochemical Expression Analysis. NCI

Thesaurus. Code C87051.

An immunohistochemical diagnostic test utilizing an antibody to detect p16 in tissues. 